10

\title{
Оптические и электрические свойства оксида графена
}

\author{
(C) А.А. Бабаев ${ }^{1}$, М.Е. Зобов ${ }^{1}$, Д.Ю. Корнилов ${ }^{2}$, С.В. Ткачев ${ }^{2}$, Е.И. Теруков ${ }^{3}$, В.С. Левицкий ${ }^{4}$ \\ ${ }^{1}$ Институт фризики им. Х.И. Амирханова Дагестанского научного центра РАН, \\ Махачкала, Россия \\ 2 „АкКо Лаб“, \\ 129110 Москва, Россия \\ ${ }^{3}$ ФТИ им. А.Ф. Иофффе РАН, \\ 194021 Санкт-Петербург, Россия \\ ${ }^{4}$ НТЦ тонкопленочных технологий в энергетике, \\ Санкт-Петербург, Россия \\ e-mail: babaev-arif@mail.ru
}

Поступила в редакцию 28.03.2018 г.

В окончательной редакции 19.07.2018 г.

Исследованы спектры комбинационного рассеяния света (КРС) и температурная зависимость электрического сопротивления оксида графена в процессе непрерывного нагрева и охлаждения в атмосфере аргона в интервале температур 300-550 К. Приведены описания и природа $D$ - и $G$-полос спектров КРС. Уменьшение интенсивности $D$-полосы после термообработки связано с уменьшением кислородосодержащих групп. Это приводит к уменьшению электрического сопротивления с ростом температуры. Обнаружена независимость сопротивления от температуры в интервале $300-370$ К, что свидетельствует о термостабильности сопротивления оксида графена.

DOI: $10.21883 / \mathrm{OS} .2018 .12 .46945 .90-18$

\section{Введение}

Большой интерес к изучению функциональных свойств оксида графена, обусловлен тем, что он является перспективным материалом для многих отраслей индустрии, имеет высокий коммерческий потенциал, выступает в качестве сырья для получения самого графена.

Оксид графена, представляющий собой случайным образом распределенные по поверхности подложки небольшие островки графена с $s p^{2}$-гибридизированными связями, окруженные обширными областями с $s p^{3}$-связями, функционализированные кислородосодержащими группами (эпоксидные, гидроксильные, карбонильные и карбоксильные) [1]. Для широкого использования оксида графена требуется, в том числе и проведение его восстановления до графена [2,3]. Термообработка является одним из эффективных способов восстановления оксида графена, в результате которой удается значительно снизить содержание кислородосодержащих групп в оксиде графена и дает возможность управления шириной запрещенной зоны в широком энергетическом интервале от ближнего ультрафиолетового до инфракрасного диапазона [3].

Несмотря на значительные успехи в развитии методов получения графена и оксида графена, достигнутые в последние годы, создание технологии воспроизводимого формирования материала на различных подложках попрежнему остается нерешенной задачей. Технологические ограничения имеющихся методов получения графена или не позволяют получать одиночные слои углеродных атомов большой площади [4], или приводят к образованию материала с мозаичной структурой, состо- ящей из взаимно развернутых мелких (около 20-30 nm) фрагментов [5].

Одним из перспективных способов получения графена, позволяющего преодолеть указанные ограничения, является метод химического расщепления природного или пиролитического графита, который уже содержит в своей структуре графеновые листы [6]. Возможность применения подобного расщепления определяется способностью графита к интеркалированию. Этот процесс приводит к увеличению расстояния между графеновыми слоями в структуре графита и в дальнейшем к его окислению. Наиболее распространенным методом химического расщепления графита является его окисление в жидкой среде с помощью перманганата калия, приводящее к образованию оксида графита [7]. Оксид графита (гидроокись графита, графитовая кислота) не имеет постоянного состава, и при максимальной степени окисления его брутто-формула может варьировать в пределах от $\mathrm{C}_{2} \mathrm{O}$ до $\mathrm{COH}$, т.е. представляет собой $\left(\mathrm{C}_{2} 0\right)_{x}(\mathrm{COH})_{x-1}$, где $0<x<1$. Оксид графита состоит из стопок окисленных графеновых листов, по обе стороны и по краям которых находятся кислородосодержащие группы. Действие ультразвуковой обработки на оксид графита приводит к образованию оксида графена [8]. Оксид графена образует устойчивые дисперсии в гидрофильных растворителях, легко восстанавливается, частично теряя кислородосодержащие группы при нагреве, интенсивном освещении или при действии химических восстановителей. В результате восстановления оксида графена образуется графен. Это обстоятельство открывает возможность получения графеновых пленок на любых смачиваемых водой подложках путем осаждения 
пленок оксида графена из водных суспензий и последующего восстановления.

Следует отметить, что опубликованные результаты исследований, выполненных в целом ряде работ $[9,10]$, указывают на наличие существенных ограничений, препятствующих созданию технологии получения графена по выше обсуждаемой технологии. Важным препятствием для воспроизводимого получения графена является неоднородность синтезируемого оксида графена. Для решения данной задачи необходимо обеспечить условия предельного окисления графита и контроля образования в чешуйках оксида графена многочисленных дефектов углеродного слоя, связанных со сменой гибридизации углерода с $s p^{2}$ на $s p^{3}$ при взаимодействии с кислородом [9]. Следовательно, указанные обстоятельства существенным образом ограничивают возможности использования оксида графита при получении графена для структур электронных приборов [11].

В настоящее время оксид графена получают окислением графита известными хорошо отработанными методами: Броди [11], Штауденмайера [12] и Хаммерca [13], причем последний способ и его модификации являются наиболее распространенными. Обсуждаемые методы позволяют получать образцы оксида графена с различными физическими параметрами из-за различных концентраций дефектов.

В настоящей работе приводятся результаты исследования спектров комбинационного рассеяния света и температурной зависимости сопротивления оксида графена (ООО „АкКо Лаб“, www.akkolab.ru) в процессе непрерывного нагрева и охлаждения в атмосфере аргона в интервале температур 300-550 К.

\section{Получение оксида графена и методика измерений}

Исследуемые пленки (рис. 1) были получены из водной дисперсии оксида графена с концентрацией $1 \mathrm{mg} / \mathrm{ml}$ путем нанесения на предметные стекла методом спин-коатинга при скорости вращения $5000 \mathrm{rpm}$. Подача дисперсии оксида графена на поверхность подложки производилась по $0.1 \mathrm{ml}$.

Очистка стеклянных подложек проводилась в несколько стадий, содержащих следующие виды обработки:

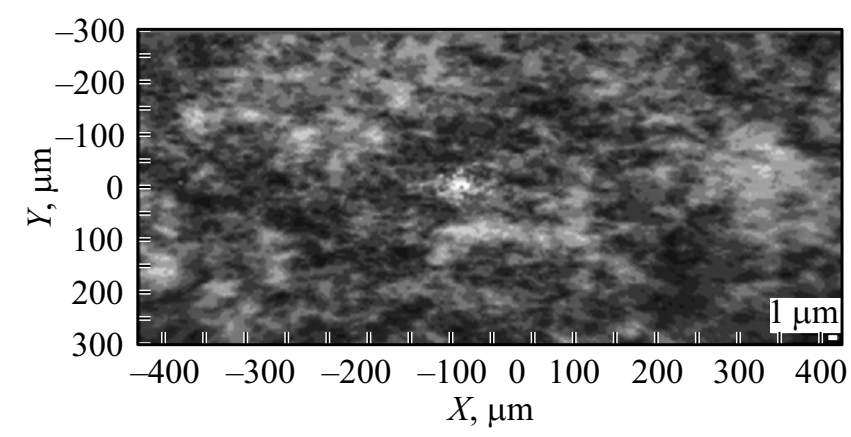

Рис. 1. Микрофотографии поверхности оксида графена. (ПАВ);

- ополаскивание деионизованной водой (ДВ);

- выдержка в водном растворе 20\% $\mathrm{NaOH}$ при комнатной температуре в течение $20 \mathrm{~min}$;

- ополаскивание ДВ;

- выдержка в водном растворе 5\% HF при комнатной температуре в течение $5 \mathrm{~min}$;

- ополаскивание ДВ;

- обработка в ультразвуковой ванне в течение $10 \mathrm{~min}$;

- ополаскивание ДВ;

- сушка на воздухе в течение $1 \mathrm{~h}$.

Исходным веществом для получения оксида графена служил китайский природный графит высокой частоты $(99.9 \%$ C), раздробленный в шаровой мельнице до фракции 200-300 $\mu \mathrm{m}$.

Оксид графена получали по модифицированному методу Хаммерса, приведенному в [14] (в перерасчете на $1 \mathrm{~g}$ природного графита).

Для получения водной дисперсии оксида графена использовали навеску массой $0.15 \mathrm{~g}$, которую помещали в цилиндрический стакан объемом $250 \mathrm{ml}$, добавляли $150 \mathrm{ml}$ деионизованной воды, затем производилась ультразвуковая обработка (частота $20.4 \mathrm{kHz}$, удельная мощность $0.1-1 \mathrm{~W} / \mathrm{cm}^{3}$ ) в течение $15 \mathrm{~min}$.

Содержащиеся в дисперсии чешуйки оксида графена латеральным размером от 0.1 до $4 \mu \mathrm{m}$ и толщиной до $1.5 \mathrm{~nm}$ (менее 10 графеновых слоев) были охарактеризованы современными физико-химическими методами анализа, результаты которых представлены в [14].

Методом рентгенофазового анализа установлено наличие уширенного интенсивного рефлекса, характерного для оксида графена $\left(2 \theta=11.5^{\circ}\right)$. Согласно данным молекулярной спектроскопии, в спектрах оксида графена присутствуют следующие пики: $D$-полоса $\left(\sim 1320 \mathrm{~cm}^{-1}\right), G$-полоса, характеризующая колебания системы $s p^{2}$ углеродных связей $\left(\sim 1582 \mathrm{~cm}^{-1}\right), 2 D$ полоса $\left(\sim 2720 \mathrm{~cm}^{-1}\right)$. Считается, что появление $D$ полосы для оксида графена свидетельствует об образовании дефектной структуры по отношению к графиту. Методами СЭМ, АСМ, ПЭМ показано, что оксид графена имеет слоистую структуру; латеральные размеры чешуек оксида графена варьируются от $100 \mathrm{~nm}$ до $4 \mu \mathrm{m}$, максимальная толщина составляет $1.5 \mathrm{~nm}$ (менее 10 графеновых слоев). Данные ИК спектроскопии и РФЭС свидетельствуют о наличии различных функциональных кислородосодержащих групп в структуре ГО: $\mathrm{C}=\mathrm{O}$, $\mathrm{C}-\mathrm{O},-\mathrm{OH}, \mathrm{C}-\mathrm{OH}, \mathrm{C}(\mathrm{O}) \mathrm{C}$. Методом C, H, N-анализа определено массовое содержание элементов в составе оксида графена (mass \%): C (58.0 \pm 1.0$), \mathrm{H}(1.5 \pm 0.5)$, $\mathrm{O}(39.0 \pm 1.0), \mathrm{N}(0)$; мольное содержание $\mathrm{C} / \mathrm{O} \sim 2 / 1$.

Исходные образцы проявляли диэлектрические свойства с сопротивлением более $10 \mathrm{GOhm} \mathrm{c} \mathrm{большой} \mathrm{-}$ более $3 \mathrm{eV}$ - шириной запрещенной зоны. В качестве контактов использована серебряная паста. Расстояние между контактами $1.7 \mathrm{~mm}$. Измерения температурной 


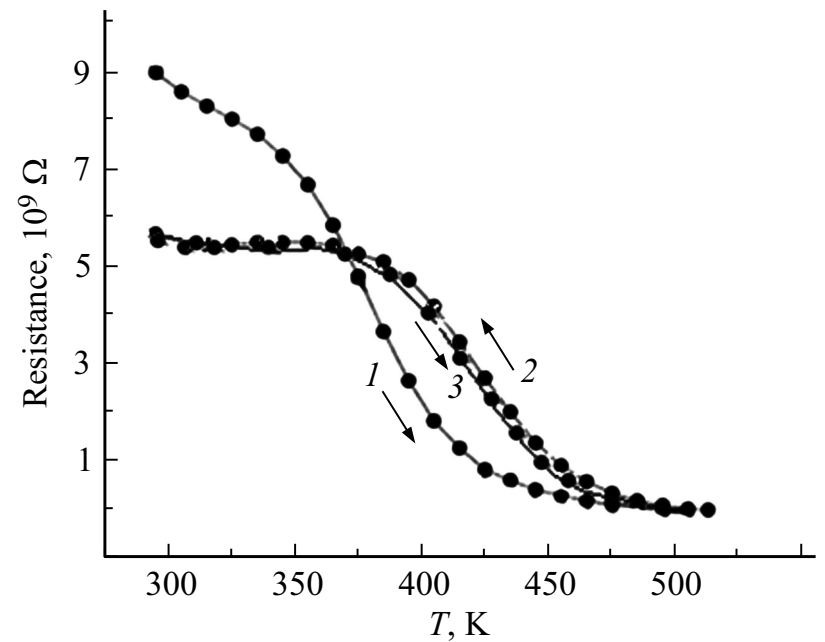

Рис. 2. Температурная зависимость сопротивления оксида графена в процессе нагрева -1 , охлаждения -2 и последующего нагрева -3 .

зависимости сопротивления исследовались при непрерывном нагреве и охлаждении со скоростью $1-1.5 \mathrm{~K} / \mathrm{min}$. Спектры комбинационного рассеяния света (КРC) получены при помощи спектрометра LabRamHR 800 при комнатной температуре. Длина волны возбуждения при измерении спектров КРС составляла $532 \mathrm{~nm}$. Мощность излучения в пучке лазера $2-3 \mathrm{~mW}$ для предотвращения перегрева образца. Измерения сопротивления выполнены на 4 образцах двухзондовым методом, используя тераомметр E6-13A.

\section{Экспериментальная часть}

На рис. 2 представлены результаты исследования температурной зависимости сопротивления в режиме динамического нагрева -1 и охлаждения -2 и последующего нагрева. Видно, что в процессе нагрева и охлаждения исходного оксида графена сопротивление уменьшается от $9 \cdot 10^{9}$ до $5.6 \cdot 10^{9} \mathrm{Ohm}$ при комнатной температуре, а в интервале температур 300-550 К сопротивление уменьшается до $0.8 \cdot 10^{9} \mathrm{Ohm}$. В температурном интервале $370-5$ К сопротивление меняется по активационному закону. В процессе охлаждения оксида графена в области температур 300-37 К сопротивление оксида графена постоянно. На температурной зависимости сопротивления наблюдается гистерезис. При последующем нагреве оксида графена сопротивление изменяется по кривой 2 рис. 2. Для объяснения полученных результатов проведены исследования оксида графена методом комбинационного рассеивания, который дает информацию о внутримолекулярных, межмолекулярных взаимодействиях и релаксационных процессах.

Элементарная ячейка графена содержит 2 атома углерода, поэтому существует шесть фононных ветвей: три акустических $(\mathrm{A})$ и три оптических $(\mathrm{O})$. Четыре из этих фононных ветвей (две акустические и две оптические) отвечают за планарные колебания атомов углерода в плоскости слоев (i), а остальные две отвечают за колебания в плоскости, перпендикулярной слоям (о). Колебания в плоскости слоев подразделяются на колебания вдоль $(\mathrm{L})$ или поперек $(\mathrm{T})$ связи $\mathrm{C}-\mathrm{C}$. Основной вклад в спектр КР дают iLO- и iTO-колебания. Схема, показывающая электронную дисперсию графена вблизи уровня Ферми в точках $K$ и $K^{\prime}$ гексагональной зоны Бриллюэна, и дисперсионные кривые в зоне Бриллюэна приведены в работе [15].

Линия $G$ в спектре КРС соответствует рассеянию света в Г-точке зоны Бриллюэна на оптическом фононе симметрии $E_{2 g}$, порожденном планарными колебаниями атомов углерода в плоскости слоев [16]. Эта полоса является дважды вырожденной и существует для всех углеродных материалов, имеющих $s p^{2}$-гибридизацию. Процесс возникновения этой линии можно пояснить следующим образом: падающий фотон с энергией $E_{\mathrm{ex}}$ резонансно возбуждает виртуальную электрон-дырочную пару, затем электрон или дырка рассеиваются на iLOили іТО-фононе с энергией $E_{\text {рп }}$ и рекомбинируют с испусканием фотона с энергией $E_{\mathrm{pt}}=E_{\mathrm{ex}}-E_{\mathrm{pп}}$. Для графена линия $G$ вырождена, однако это вырождение может быть снято применением одноосной деформации к графеновому слою или при сворачивании графенового листа в углеродную нанотрубку. В этом случае произойдет расщепление линии $G[17,18]$.

Спектральная линия $2 D$ обусловлена резонансным рассеянием света с участием двух фононов с одинаковой энергией, но противоположным направлением импульса. Рассеяние происходит в $K$-точке зоны Бриллюэна и вызвано симметричными колебаниями растяжениясжатия графенового кольца. Падающий фотон возбуждает электрон-дырочную пару вблизи $K$-точки зоны Бриллюэна. Электрон неупруго рассеивается на іТОфононе в точку $K^{\prime}$. Поскольку в процессе КРС должны выполняться законы сохранения энергии и импульса, то электрон обязан рассеяться обратно в $K$-точку, прежде чем произойдет рекомбинация с дыркой. В случае $2 D$ линии обратное рассеяние электрона происходит за счет второго іТО-фонона. Аналогичный процесс может происходить и для дырки. Эти процессы получили название двойного резонанса, так как появление и рассеяние фотона и первый или второй процесс рассеяния фононов совпадают с электронными уровнями в графене.

Другой важной особенностью в спектрах КРС является линия $D$, появление которой обусловлено рассеянием на дефектах. Эта линия, так же как и $2 D$, возникает при рассеянии на іТО-фононе вблизи $K$-точки зоны Бриллюэна $[19,20]$, однако в отличие от $G$ - и $2 D$-линий для выполнения закона сохранения импульса необходим дефект. В этом случае электрон неупруго рассеивается на іТО-фононе в $K^{\prime}$-точку, а затем упруго рассеивается на дефекте обратно в $K$-точку $[21,22]$. Поскольку процесс рассеяния происходит с участием одного фонона, то частотный сдвиг для $D$-линии составляет половину 

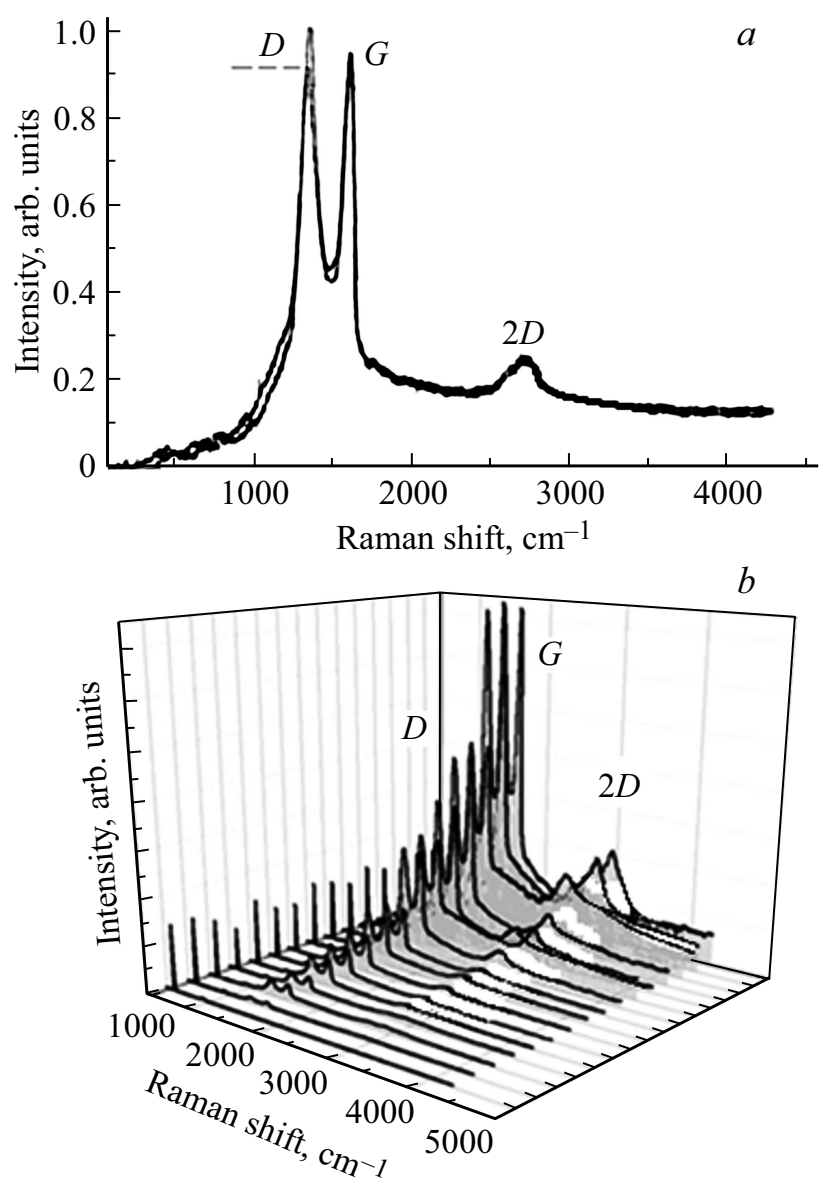

Рис. 3. Спектры комбинационного рассеяния оксида графена $(a)$ до и после нагрева и охлаждения при $T=300 \mathrm{~K}$. $(b)$ массив спектров КРС как функция числа слоев, расположенных по степени возрастания их интенсивности.

значения от $2 D$-линии. Дефектом может являться любое нарушение симметрии решетки графена, например, $s p^{3}$-дефекты [23], вакансии [24,25], границы зерен [26] и др. [27-29].

На рис. 3, $а$ приведены типичные спектры КРС оксида графена. Видно, что в спектрах КРС присутствуют типичные узкие линии с положением максимума вблизи $1320 \mathrm{~cm}^{-1}$ (линия $D$ ) и $1582 \mathrm{~cm}^{-1}$ (линия $G$ ), а также $2 D$-полоса $\sim 2720 \mathrm{~cm}^{-1}$.

На рис. 3, $b$ приведен массив спектров КРС образца оксида графена. Интенсивность спектров КРС в различных точках слоя оксида графена существенно меняется и зависит от толщины слоя. Однако во всех спектрах существуют две основные $D$ - и $G$-линии. Используя результаты работы [30], авторы которой показали зависимость толщины слоя оксида графена от интенсивности линии $G$ в спектрах КРС, определили толщину слоя оксида графена в диапазоне от 1 до 10 слоев.

Природа данных пиков связана с колебаниями $s p^{3}$-гибридизированных (полоса $D)$ и $s p^{2}-$ (полоса $G$ ) фрагментов углеродной сетки [31,32]. Отношение интенсивностей $D$ - и $G$-полос $\left(I_{D} / I_{G}\right)$ пропорционально количественному отношению областей со связями углерода $s p^{3}$-гибридизации и областей со связями углерода $s p^{2}$-гибридизации, а также количественному отношению атомов кислорода и атомов углерода $(\mathrm{O} / \mathrm{C})$ в структуре оксида графена [33]. С увеличением температуры оксида графена отношение интенсивности $\left(I_{D} / I_{G}\right)$ уменьшается от 1 до 0.95 (рис. 3), что свидетельствует о том, что в оксиде графена уменьшается содержание кислорода и увеличивается доля областей углеродной сетки с $s p^{2}$ связями. Высокая интенсивность и значительная ширина линии $D$ в спектрах КРС указывает на большую концентрацию структурных дефектов. Используя результаты работы [34], в которой были предложены модель и методы расчета концентрации структурных дефектов в графене, нами была определена концентрация дефектов в структуре оксида графена $N_{d} \sim 1 \cdot 10^{14} \mathrm{~cm}^{-2}$. Удаление кислородосодержащих функциональных групп сопровождается уменьшением электрического сопротивления, приводит к изменению структуры оксида графена, в результате наблюдается гистерезисное поведение температурной зависимости сопротивления, которое исчезает при последующем нагреве. Из-за сильной связи кислорода с углеродом в интервале температур 300-370 K сопротивление оксида графена термостабильно. Дальнейшее уменьшение сопротивления от $0.8 \cdot 10^{9} \mathrm{Ohm}$ будет сопровождаться при более высоких температурах, свыше 550 К.

\section{Заключение}

Получены слои оксида графена с латеральными размерами чешуек от 0.1 до $4 \mu \mathrm{m}$. Результаты исследования спектров КРС, в частности уменьшение интенсивности $D$-полосы после термообработки от 1 до 0.95 , связано с уменьшением содержания кислородосодержащих групп. Сопротивление оксида графена уменьшается с ростом температуры за счет уменьшения содержания кислородосодержащих групп. В интервале температур 300-370 К сопротивление оксида графена термостабильно. При этих температурах кислородосодержащие группы находятся в сильно связанном состоянии с углеродом. Для большего уменьшения кислородосодержащих групп необходимы более высокие температуры.

\section{Список литературы}

[1] Singh V., Joung D., Zhai L. // Proress in Material Science. 2011. V. 56. P. 1178.

[2] Pei S., Cheng Hu-M. // Carbon. 2012. V. 50. P. 3210.

[3] Stankovich S., Dikin D., Finer R.D. et al. // Carbon. 2007. V. 45. P. 1558.

[4] Allen M.J., Tung V.C., Kaner R.B. // Chem. Rev. 2010. V. 110. N LP.132.

[5] Bae S., Kim H., Lee Y. // Nat. Nanotechnol. 2010. V. 5. N 8. P. 574-578.

[6] Novoselov K., Fal V., Colombo L. Gellert P. // Nature. 2012. V. 490. N 7419. P. 192-200. 
[7] Offeman R., Hummers W. // J. Am. Chem. Soc. 1958. V. 80. P. 1339-1339.

[8] Bao Q., Eda G., Chhowalla M. // Nat. Chem. 2010. V. 2. N 12. P. 1015-1024.

[9] Park S., Ruoff R.S. // Nat. Nanotechnol. 2009. Vol. 4. N 4. P. 217-224.

[10] Chen W., Yan L. // Nanoscale. 2010. V. 2. P. 559.

[11] Eda G., Fanchini G., Chhowalla M. // Nat. Nanotechnol. 2008. V. 3. N 5. P. 270-274.

[12] Soldano C., Mahmood A., Dujardin E. // Carbon. 2010. V. 48. N 8. P. 2127-2150.

[13] Brodie B.C. // Ann. Chim. Phys. 1860. V. 59. P. 466-472.

[14] Ткачев С.В., Буслаева Е.Ю., Наумкин А.В. // Неорганические материалы. 2012. Т. 48. № 8. С. 909-915.

[15] Beams R., Cancado L.G., Novotny L. // J. Phys. Condens. Matter. 2015. V. 27. P. 083002.

[16] Nemanich R.J., Solin S.A. // Phys. Rev. B. 1979. V. 20. P. 392.

[17] Ni Z.H., Chen W., Fan X.F. // Phys. Rev. B. 2008. V. 77. P. 115416.

[18] Jorio A., Souza Filho A.G., Dresselhaus G. // Phys. Rev. B. 2002. V. 65. P. 155412.

[19] Thomsen C., Reich S. // Phys. Rev. Lett. 2000. V. 85. P. 5214.

[20] Das A., Chakraboty B., Sood A.K. // Bull. Mater. Sci. 2008. V. 31. P. 579.

[21] Saito R., Jorio A., Souza Filho A.G. // Phys. Rev. Lett. 2001. V. 88. P. 027401.

[22] Pimenta M.A., Dresselhaus G., Dresselhaus M.S. // Phys. Chem. Chem. Phys. 2007. V. 9. P. 1276.

[23] Eckmann A., Felten A., Mishchenko A. // Nano Lett. 2012. V. 12. P. 3925.

[24] Lucchese M.M., Stavale F., Ferreira E.H. // Carbon. 2010. V. 48. P. 1592.

[25] Cancado L.G., Jorio A., Ferreira E.H.M. // Nano Lett. 2001. V. 11. P. 3190.

[26] Lespade P., Marchand A., Couzi M. // Carbon. 1984. V. 22. P. 375 .

[27] Casiraghi C., Hartschuh A., Qian H. // Nano Lett. 2009. V. 9. P. 1433.

[28] Beams R., Cancado L.G., Novotny L. // Nano Lett. 2011. V. 11. P. 1177.

[29] Cancado L.G., Pimenta M.A., Neves B.R.A. // Phys. Rev. Lett. 2004. V. 93. P. 247401.

[30] Diez-Betriu X., Alvarez-Garsia S., Botas C. // J. Mater. Chem. C. 2013. V. LP. P. 6905.

[31] Kudin K.N., Ozbas B., Schniepp H.C. // Nano Letters. 2008. V. 8. P. 36.

[32] Александров Г.Н., Смагулова С.А., Капитонов А.Н. // Российские нанотехнологии. 2014. Т. 9. С. 18.

[33] Lucchese M.M., Stavale F., Ferreira E.H.M. // Carbon. 2010. V. 48. P. 1592.

[34] Yang K., Hu K., Wang Y., Yu T. // Carbon. 2013. V. 52. P. 528. 